\title{
Assessment of the Profitability of an Apartment Building Complex Using a Stochastic Cash-Flow
}

\author{
Nazim Noueihed ${ }^{1}$, Fadi Asrawi ${ }^{2} \&$ Najoie Nasr $^{2}$ \\ ${ }^{1}$ Department of Mathematics, Division of Mathematical Sciences, Faculty of Arts \& Sciences, Haigazian \\ University, Beirut, Lebanon \\ ${ }^{2}$ Faculty of Business Administration \& Economics, Haigazian University, Beirut, Lebanon \\ Correspondence: Nazim Noueihed, Department of Mathematics, Division of Mathematical Sciences, Faculty of \\ Arts \& Sciences, Haigazian University, Beirut, Lebanon. E-mail: nazim.noueihed@haigazian.edu.lb
}

Received: March 13, 2019

Accepted: May 15, 2019 Online Published: May 17, 2019

doi:10.5539/emr.v8n1p44

URL: https://doi.org/10.5539/emr.v8n1p44

\begin{abstract}
The economic feasibility of apartment building complexes is mainly done by using one of the economic analysis methods: present worth, future worth, annual worth, rate of return, or benefit-cost ratio. The cash-flow used is based on the assumption that a certain fraction of the apartments will be sold during the construction period, and the rest equally sold annually over a certain period of time. This model may work sometimes, but its estimated profitability is inaccurate. The actual cash-flow to be used is stochastic. In this paper, we shall use a cash-flow with random separation time between successive sales of apartments after the construction period. We shall find a compact form of the expected present worth, and determine a range for the annual discount rate so that the project is profitable.
\end{abstract}

Keywords: stochastic cash-flow, discount rate, present worth, random variable, probability distribution, moment generating function

\section{Background and Introduction}

A financial investment in a project is random or under risk if at least one of its parameters is a random variable with a known probability distribution.

In reality, most of real-life investments are random with stochastic cash-flows. Deterministic cash-flows are used when the variances of the concerned random variables are too small so it can be neglected and the variable is represented by its expected value or mean.

The economic worth of apartment building complexes is usually based on a deterministic cash-flow consisting of a construction period with corresponding annual costs plus a heavy initial cost. Some of the apartments are assumed to be sold annually after construction within a certain time period at a given price.

In reality, the time between the sale of an apartment and the next one is unpredictable so it is a random variable. This promotes the use of a stochastic cash-flow for the given model.

In this paper, we will consider the separation times between successive sales after construction as our random variable, and the construction costs as equally distributed over the construction period.

In the analysis that we use, the concept of moment generating functions of random variable will prove to be a powerful tool that leads to a closed form of the expected present worth and the rest of analysis methods except for the rate of return.

\section{Literature Review}

The most important resource for a real estate investment is cash flow. Many real estate investments fail due to a lack of liquidity for supporting their daily activities than because of inadequate management of other resources. Stochastic processes, which imitate the uncertain trend of target variables over time are used to carry out dynamic modelling of the outcome of investments in conditions of uncertainty (Simon, 2002). The main concerns of the modelling of the outcome of investments in conditions of uncertainty have focused on capital costs, the probability of credit default and income flows. Stochastic modelling of rental income have been made by Hughes (1995) and De Wit and van Dijk (2003). Stochastic processes modelling the development of real 
estate loans values were made by Kau et al. (2006). Stochastic processes modelling the discount factor were used by Schwartz (1997) and Downs (2000) and Sing optimized the timing of a real estate development under uncertainty (Sing, 2000).

In most of the research, the uncertainties were applied at a single point in time not the interdependence of trends of costs over time. Pfnür and Armonat (2001) investigated the uncertainty of the cash flow trend in an empirical survey of European investment managers. The purpose was to find how much in a ten-year forecast forecasted cash flow items differed on average from actual figures. The standard deviation of the cash flow items in the financial plan for the property was also asked for. For all those surveyed, the average difference makes up 40 percent of the total costs of a property, which is quite considerable. Decision makers tended to overestimate rather than underestimate their own forecasting abilities.

The aim of achieving positive NPV through the decisions to buy and sell real estate is a strategic decision in such investments. The assumptions of the use of the NPV rule is that stock market is fundamentally efficient, the only risk is systematic risk and the firm's goal is to maximize shareholder wealth. This maximization of shareholder wealth can be achieved by investing in all projects that have positive NPV when the cash flows associated with the projects are discounted and summed using the appropriate cost of capital. Only positive NPV contribute to added value to the firm.

The value of the firm is equal to the sum of the values of capital projects/business within it (Myers, 1984). This rule applies to any property investment undertaken by the firm. The NPV decision rule is used to allocate capital budgeting and serves as the basis for the valuation of a property investment or development project. The project is accepted when its NPV is zero or positive. The project is rejected when the NPV is negative (Clark et al., 1989).

The efficient market hypothesis stipulates that all assets are valued according to their expected cash flows. Thus, the value of real estate to a particular firm depends upon the cash flow produced by the asset at its current use and in a well-functioning market, the present value of a project is equal to its market value. The capital budgeting theory stipulates that a project's NPV is the present value of its future cash inflows, subtracted from the present value of the project's expected cash outflows (costs). Both the cash inflows and outflows are discounted at a rate that reflects the systematic risk of these expected future cash flows, the positive NPVs arising from property development or property investment represent an increase in the value of the firm (Brealey $\&$ Myers, 2000).

Investments in underpriced properties will increase the value of the company by the amount of the NPV earned (Brown \& Matysiak, 2000).

The sale of a property is only desired if the net sale profits exceed the present value of the net future cash flows generated from the property from the seller's perspective. On the other hand, from the buyer's perspective the purchase makes economic sense only if the purchase has a positive NPV value. The price of the property usually is contingent upon whether the property may have alternative uses, it could be used more efficiently and the amount of buyers interested to buy the property.

The internal rate of return provided by the acquired property with a positive NPV should be greater than that required for their level of risk. Investing in an underpriced property will increase the value of the company by the amount of the NPV earned.

In an efficient capital market, the NPV is rapidly reflected into the stock prices of the firm. Geographical focus of the property investments, positive information conveyed by project specific private debt and positive signal when acquisitions are financed by equity of financial institutions (Campbell et al., 2003).

Asymmetric valuations change the worth of the property for different investors. The main reasons for asymmetric valuations arise from differences in risk preferences; discount rates; marginal tax rates; and production capabilities. An investment appraisal determines the worth of the property. This will establish whether a new investment should be purchased and the price to pay for it. The price established could be less than the asking price indicating that the investor/purchaser's individual circumstances are more suited to the property. The differences in price levels are due to different investment objectives and strategy, financial and tax status, portfolio issues, required rate of return, etc. The worth of a property to a specific investor will reflect the investor's specific requirements like the holding period, internal rate of return, cost of capital etc. 


\section{Definitions of Technical Symbols}

P: Initial cost

B: Price of an apartment

$\mathrm{N}$ : Number of apartments

i: Annual discount rate

PW: Net present worth

AW: Net annual worth

B/c: Benefit-cost ratio

$M(t)$ : Moment generating function

T: Separation time between successive sales

$\mathrm{N}\left(\mu, \sigma^{2}\right)$ : Normal distribution

Exp (a): Exponential distribution with parameter "a"

$G(\alpha, \beta)$ : Gamma distribution with parameters $\alpha$ and $\beta$

\section{The Mathematical Model}

- The initial investment at time 0 is $\mathrm{P}$

- The construction period lasts "J" years

- A certain fraction " $\alpha$ " of the apartments will be sold during construction

- The down payment on the apartment sold during construction is " $D$ "

The construction of the project starts with an initial cost "P". It lasts a period of "J" years. The construction cost during the "J" years is equally distributed on annual basis with a value " $\mathrm{C}$ ".

A number $\alpha \mathrm{N}=\mathrm{K}$ apartments will be sold during the construction period. A down payment " $\mathrm{D}$ " is received on every apartment sold. The sum of the down payments will be equally split over the years of construction. Those apartments sold during construction will be delivered exactly at the end of construction, and the rest of the cost will be paid by purchasers in full. The apartments that remain after construction will be sold, but the time between the successive sales is a random variable with a given probability distribution.

The following is to be noted:

- The number of apartments sold during construction is $\mathrm{K}$, and those to be sold after construction is $\mathrm{N}-\mathrm{K}=\mathrm{L}$.

- The positive cash-flow for the first "J" years is $\left(\frac{K D}{J}\right)$ every year. And the positive cashflow to be received at year "J" is: $\mathrm{K}(\mathrm{B}-\mathrm{D})$.

We define the following random variables:

$\mathrm{T}_{1}$ : time from year "J" to the first apartment sold.

$\mathrm{T}_{2}$ : time between the first and second sales.

$\mathrm{T}_{\mathrm{L}}$ : Time between the last two apartments sold.

We shall assume that $\mathrm{T}_{1}, \mathrm{~T}_{2}, \ldots, \mathrm{T}_{\mathrm{L}}$ are (i i d)

The model is represented by the following stochastic cash-flow: 


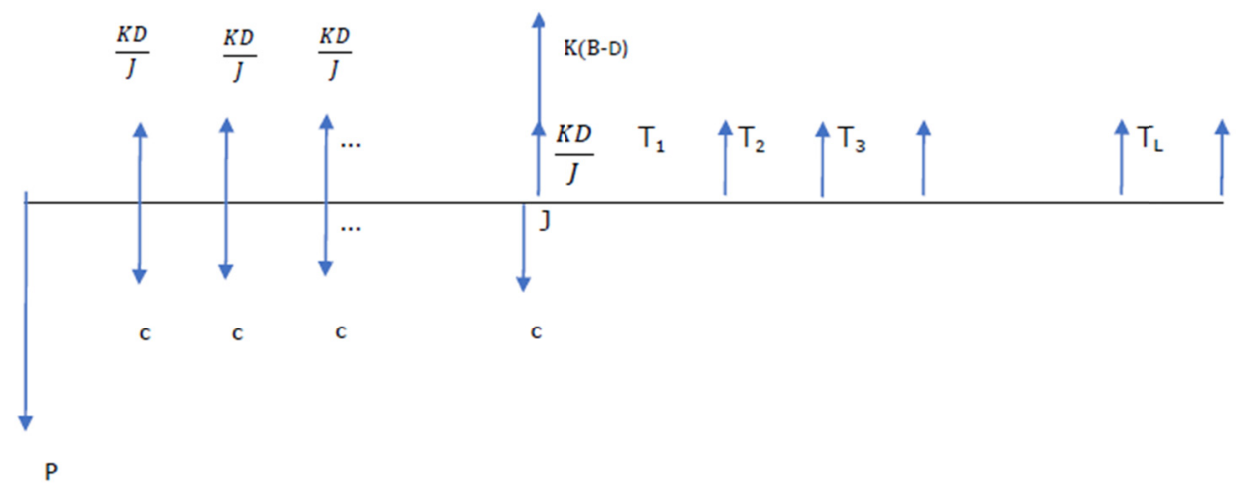

No generality is lost if we assume continuous compounding to make a smooth analysis.

For a given discount rate/year "i", we shall calculate the present worth of the cash-flow as the sum of the present worth up to year "J" which will be $\mathrm{PW}_{1}$, and the present worth after "J" years which will be $\mathrm{PW}_{2}$.

$$
\begin{gathered}
P W_{1}=\left(\frac{K D}{J}\right)\left(e^{-i}+e^{-2 i}+\cdots+e^{-J i}\right)-c\left(e^{-i}+e^{-2 i}+\cdots+e^{-J i}\right)+K(D-B) e^{-J i}-P \\
=\left(\frac{K D}{J}-c\right)\left(\sum_{m=1}^{J} e^{-m i}\right)+K(D-B) e^{-J i}-P
\end{gathered}
$$

Let $\mathrm{Y}_{1}=\mathrm{T}_{1}, \mathrm{Y}_{2}=\mathrm{T}_{1}+\mathrm{T}_{2}, \ldots, \mathrm{Y}_{\mathrm{L}}=\mathrm{T}_{1}+\mathrm{T}_{2+\cdots}+\mathrm{T}_{\mathrm{L}}$

$$
P W_{2}=B e^{-\left(J+Y_{1}\right) i}+B e^{-\left(J+Y_{2}\right) i}+\cdots+B e^{-\left(J+Y_{L}\right) i}=B e^{-J i}\left(e^{-Y_{1} i}+e^{-Y_{2} i}+\cdots+e^{-Y_{L} i}\right)
$$

Now for a given random variable $\mathrm{x}$, the moment generating function is:

$$
M(J)=E\left(e^{J x}\right)
$$

Since $T_{1}, T_{2}, \ldots, T_{L}$ are (i i d) which can be described by a single random variable $T$, the moment generating function of $\mathrm{T}_{1}+\mathrm{T}_{2}+\cdots+\mathrm{T}_{L}=M^{L}(\mathrm{~J})$ where $\mathrm{M}(\mathrm{J})$ is the moment generating function of $\mathrm{T}$.

$$
\begin{gathered}
\Rightarrow E\left(e^{-Y_{1} i}\right)=M(-i) \\
E\left(e^{-Y_{2} i}\right)=M^{2}(-i) \\
\vdots \\
E\left(e^{-Y_{L} i}\right)=M^{L}(-i) \\
\Rightarrow E\left(P W_{2}\right)=B e^{-J i}\left[M(-i)+M^{2}(-i)+\cdots+M^{L}(-i)\right]=B e^{-J i}\left[\frac{M^{(L+1)}(-i)-1}{M(-i)-1}-1\right]
\end{gathered}
$$

Since $\mathrm{PW}_{1}$ does not contain any randomness, then $E\left(P W_{1}\right)=P W_{1}$

$$
\Rightarrow E(P W)=\left(\frac{M D}{J}-c\right)\left(\sum_{m=1}^{L} e^{-m i}\right)+k(B-D) e^{-J i}-P+B e^{-J i}\left[\frac{M^{(L+1)}(-i)-1}{M(-i)-1}-1\right]
$$

We will find a range of values of the annual discount rate "i" for which $\mathrm{E}(\mathrm{PW})>0$.

That is, we solve the following inequality for " $\mathrm{i}$ "

$$
\left.\left(\frac{M D}{J}-c\right)\left(\sum_{m=1}^{L} e^{-m i}\right)+k(B-D) e^{-J i}+B e^{-J i}\left[\frac{M^{(L+1)}(-i)-1}{M(-i)-1}-1\right]-P>0 \text { (inequality } 1\right)
$$

The above inequality has a range of $i<0<i^{*}$ so that if the investor's annual discount rate falls into the region, then the investment is profitable.

To show that such a range always exists, let $f(i)=E(P W(i))$

$$
f(0)=\left(\frac{K D}{J}-c\right) J+k(B-D)-P+L B=-J c-P+(K+L) B=-J C-P+N B
$$

Definitely B is set so that the Total Revenue NB > Total Cost: JC + D 
The derivative $\mathrm{f}(\mathrm{i})<0$, so $\mathrm{f}(\mathrm{i})$ is decreasing.

Now, $\lim _{1 \rightarrow \infty} f(i)=-P<0$ so $f(i)=0$ has exactly one solution $i^{*}$.

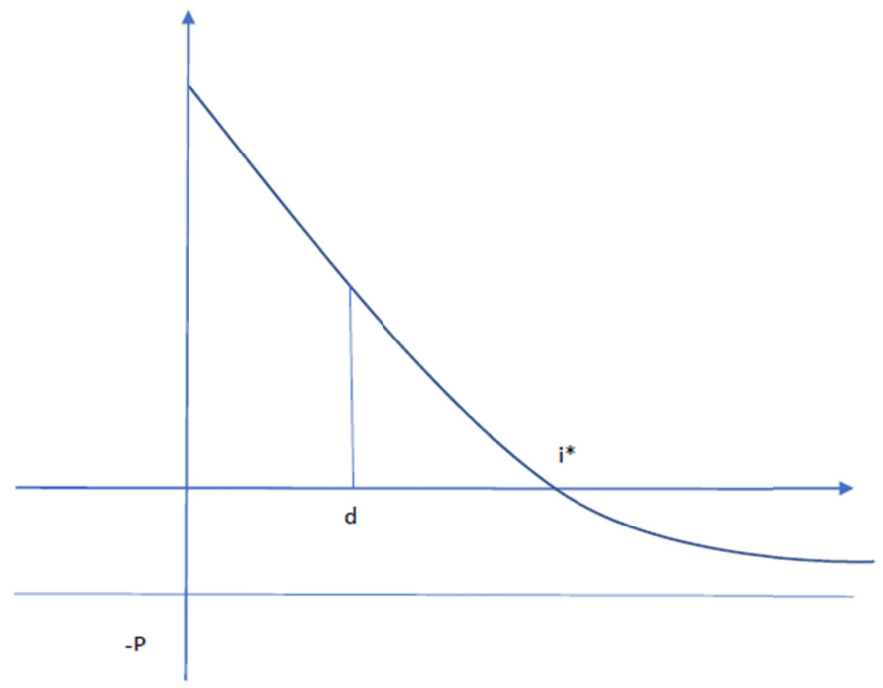

Graph of the function $f(i)=E(P W(i))$

$i^{*}$ : Root of $f(i)=0$

d: Investor's discount rate

If $\mathrm{d}$ is in the $\left(0, \mathrm{i}^{*}\right)$ interval, then $\mathrm{E}(\mathrm{PW}(\mathrm{d} 1))>0$.

\section{Numerical Examples}

The following numerical examples are based on three main distributions used mainly for waiting times: The exponential, the normal, and the general gamma.

The mean of the distribution is based on the average period to sell the remaining apartments after construction. It is calculated as: if $\mathrm{A}$ is the average time, then the mean $=\frac{A}{L}$, where $\mathrm{L}$ is the number of remaining apartments.

Values of the parameters

$\mathrm{N}=30, \mathrm{~K}=10, \mathrm{~L}=20, \mathrm{~J}=2, \mathrm{C}=3, \mathrm{P}=2, \mathrm{~B}=0.4, \mathrm{D}=0.1$ (costs and prices are in $\$$ million)

5.1 Four Examples When TIs Exponentially Distributed

1) $\mathrm{A}=1, \mathrm{~T}=\operatorname{Exp}(20)$

Inequality 1 becomes:

$$
0.5 e^{-2 i}-2.5 e^{-i}+0.4 e^{-2 i}\left[\frac{(1+0.05 i)^{-21}-1}{(1+0.05 i)^{-1}-1}-1\right]-2>0
$$

The profitable range is $(0,33 \%)$

2) $\mathrm{A}=2, \mathrm{~T}=\operatorname{Exp}(10)$

Inequality 1 becomes:

$$
0.5 e^{-2 i}-2.5 e^{-i}+0.4 e^{-2 i}\left[\frac{(1+0.1 i)^{-21}-1}{(1+0.1 i)^{-1}-1}-1\right]-2>0
$$

The profitable range is $(0,25 \%)$

3) $\mathrm{A}=3, \mathrm{~T}=\operatorname{Exp}(20 / 3)$

Inequality 1 becomes:

$$
0.5 e^{-2 i}-2.5 e^{-i}+0.4 e^{-2 i}\left[\frac{(1+0.15 i)^{-21}-1}{(1+0.15 i)^{-1}-1}-1\right]-2>0
$$


The profitable range is $(0,22 \%)$

4) $\mathrm{A}=4, \mathrm{~T}=\operatorname{Exp}(5)$

Inequality 1 becomes:

$$
0.5 e^{-2 i}-2.5 e^{-i}+0.4 e^{-2 i}\left[\frac{(1+0.2 i)^{-21}-1}{(1+0.2 i)^{-1}-1}-1\right]-2>0
$$

The profitable range is $(0,19.5 \%)$

\subsection{Four Examples When T Is Normally Distributed}

1) $\mathrm{A}=1, \mathrm{~T}=\mathrm{N}(0.05,0.01)$

Inequality 1 becomes:

$$
0.5 e^{-2 i}-2.5 e^{-i}+0.4 e^{-2 i}\left[\frac{e^{\left(-1.05 i+0.105 i^{2}\right)}-1}{e^{\left(-0.05 i+0.005 i^{2}\right)}-1}-1\right]-2>0
$$

The profitable range is $(0,29 \%)$

2) $\mathrm{A}=2, \mathrm{~T}=\mathrm{N}(0.1,0.01)$

Inequality 1 becomes:

The profitable range is $(0,24 \%)$

$$
0.5 e^{-2 i}-2.5 e^{-i}+0.4 e^{-2 i}\left[\frac{e^{\left(-2.1 i+0.105 i^{2}\right)}-1}{e^{\left(-0.1 i+0.005 i^{2}\right)}-1}-1\right]-2>0
$$

3) $\mathrm{A}=3, \mathrm{~T}=\mathrm{N}(0.15,0.01)$

Inequality 1 becomes:

$$
0.5 e^{-2 i}-2.5 e^{-i}+0.4 e^{-2 i}\left[\frac{e^{\left(-3.15 i+0.105 i^{2}\right)}-1}{e^{\left(-0.15 i+0.005 i^{2}\right)}-1}-1\right]-2>0
$$

The profitable range is $(0,23 \%)$

4) $\mathrm{A}=4, \mathrm{~T}=\mathrm{N}(0.2,0.01)$

Inequality 1 becomes:

$$
0.5 e^{-2 i}-2.5 e^{-i}+0.4 e^{-2 i}\left[\frac{e^{\left(-4.2 i+0.105 i^{2}\right)}-1}{e^{\left(-0.2 i+0.005 i^{2}\right)}-1}-1\right]-2>0
$$

The profitable range is $(0,18 \%)$

5.3 Four Examples When T Has a Gamma Distribution and the Average Times Are Doubled

1) $\mathrm{A}=2, \mathrm{~T}=\mathrm{G}(1.1,0.9)$

Inequality 1 becomes:

$$
0.5 e^{-2 i}-2.5 e^{-i}+0.4 e^{-2 i}\left[\frac{(1+0.09 i)^{-23}-1}{(1+0.09 i)^{-1}-1}-1\right]-2>0
$$

The profitable range is $(0,30 \%)$

2) $\mathrm{A}=4, \mathrm{~T}=\mathrm{G}(1.1,0.18)$

Inequality 1 becomes:

$$
0.5 e^{-2 i}-2.5 e^{-i}+0.4 e^{-2 i}\left[\frac{(1+0.18 i)^{-23}-1}{(1+0.18 i)^{-1}-1}-1\right]-2>0
$$

The profitable range is $(0,24 \%)$

3) $\mathrm{A}=6, \mathrm{~T}=\mathrm{G}(1.1,0.27)$

Inequality 1 becomes: 


$$
0.5 e^{-2 i}-2.5 e^{-i}+0.4 e^{-2 i}\left[\frac{(1+0.27 i)^{-23}-1}{(1+0.27 i)^{-1}-1}-1\right]-2>0
$$

The profitable range is $(0,18 \%)$

4) $\mathrm{A}=8, \mathrm{~T}=\mathrm{G}(1.1,0.36)$

Inequality 1 becomes:

$$
0.5 e^{-2 i}-2.5 e^{-i}+0.4 e^{-2 i}\left[\frac{(1+0.36 i)^{-23}-1}{(1+0.36 i)^{-1}-1}-1\right]-2>0
$$

The profitable range is $(0,13 \%)$

\section{Conclusion}

When numerical examples were applied on the three main distributions used mainly for waiting times, the profitable range varied as follows:

For the exponential distribution, the lowest profitable range was $(0,19.5 \%)$ and the highest range was $(0,33 \%)$.

For the normal distribution, it ranged from $(0,18 \%)$ to $(0,29 \%)$ and for the general gamma distribution, the range of profitability varied between $(0,13 \%)$ and $(0,30 \%)$. One can see that as average waiting time increased, the profitability range decreased no matter the shape of the distribution. However, for same average waiting time, for instance when A was set at 4, the general gamma distribution gave the highest profitability range of $(0,24 \%)$ compared to a $(0,19.5 \%)$ for exponential and $(0,18 \%)$ in normal distribution.

In this paper, the model gave a range for the discount rate for the investors so that the project is profitable.

\section{References}

Brealey, R. A., \& Myers, S. C. (2000). Principles of Corporate Finance. McGraw-Hill, New York, NY.

Brown, G. R., \& Matysiak, G. A. (2000). Real estate investment: A capital market approach (pp. 9-10). Harlow: Financial Times Prentice Hall. https://doi.org/10.1023/A:1007879805481

Campbell, R. D., Petrova, M., \& Sirmans, C. F. (2003). Wealth effects of diversification and financial deal structuring: evidence from REIT property portfolio acquisitions. Real Estate Economics, 31(3), $347-366$. https://doi.org/10.1111/1540-6229.00069

Clark, J. J., Hindelang, T. J., \& Pritchard, R. E. (1989). Capital budgeting: planning and control of capital expenditures. Prentice Hall.

De Wit, I., \& van Dijk, R. (2003). The global determinants of direct office real estate returns. Journal of Real Estate Finance and Economics, 26(1), 27-45. https://doi.org/10.1023/A:1021518130915

Dixit, A. K., \& Pyndick, R. S. (1994). Investment Under Uncertainty. Princeton University Press, Princeton, NJ.

Downs, D. H. (2000). Assessing the real estate pricing puzzle: A diagnostic application of the stochastic discounting factor to the distribution of REIT returns. Journal of Real Estate Finance and Economics, 20(2), 155-175. https://doi.org/10.1023/A:1007825204636

Hughes, W. T. (1995). Risk analysis and asset valuation: A Monte Carlo simulation using stochastic rents. Journal of Real Estate Finance and Economics, 11, 177-187. https://doi.org/10.1007/BF01098661

Kau, J. B., Keenan, D. C., \& Smurov, A. A. (2006). Reduced form mortgage pricing as an alternative to option-pricing models. Journal of Real Estate Finance and Economics, 33, 183-196. https://doi.org/10.1007/s11146-006-9981-7

Myers, S. C. (1984). Finance theory and financial strategy. Interfaces, 14(1), $126-137$. https://doi.org/10.1287/inte.14.1.126

Pfnür, A., \& Armonat, S. (2001). Mmobilienkapitalanlage institutioneller Investoren, Working Paper Series. Department for Public Management No. 26, University of Hamburg, Hamburg.

Pfnür, A. \& Armonat, S. (2004). Asset allocation versus entrepreneurial decisions in real estate investment. Briefings in Real Estate Finance, 4(2), 131-146. https://doi.org/10.1002/bref.128

Schwartz, E. S., \& Moon, C. (2001). Rational pricing of internet companies revisited. The Financial Review, 36, 7-26. https://doi.org/10.1111/j.1540-6288.2001.tb00027.x

Schwartz, E. S. (1997). The stochastic behavior of commodity prices: implications for valuation and hedging. The 
Journal of Finance, 52(3), 923-973. https://doi.org/10.1111/j.1540-6261.1997.tb02721.x

Simon, S. (2002). Momentum effects and mean reversion in real estate securities. Journal of Real Estate Research, 23(1/2), 47-64.

Sing, T. F. (2001). Optimal timing of a real estate development under uncertainty. Journal of Property Investment \& Finance, 19(1), 35-52. https://doi.org/10.1108/14635780110365352

\section{Copyrights}

Copyright for this article is retained by the author(s), with first publication rights granted to the journal.

This is an open-access article distributed under the terms and conditions of the Creative Commons Attribution license (http://creativecommons.org/licenses/by/4.0/). 